\title{
RENCANA ADAPTASI PADA WILAYAH RAWAN PENURUNAN TANAH, KECAMATAN CENGKARENG, JAKARTA BARAT
}

\author{
Siti Wahyuningtyas Maulidiny ${ }^{1)}$, Parino Rahardjo ${ }^{21}$, Suryono Herlambang ${ }^{3)}$
}

1)Program Studi S1 PWK, Fakultas Teknik, Universitas Tarumanagara, ningtyasmaulidiny@gmail.com

2)Program Studi S1 PWK, Fakultas Teknik, Universitas Tarumanagara, parinor19@gmail.com

3)Program Studi S1 PWK, Fakultas Teknik, Universitas Tarumanagara, s.herlambang@gmail.com

Masuk: 03-08-2021, revisi: 03-09-2021, diterima untuk diterbitkan: 23-10-2021

\begin{abstract}
Abstrak
Penurunan muka tanah merupakan salah satu fenomena alam yang terjadi di Kota Jakarta salah satu yaitu pada Kecamatan Cengkareng. Penurunan muka tanah disebabkan oleh beberapa faktor seperti, faktor alami, faktor pengambilan air tanah, dan faktor massa bangunan. Penurunan tanah ini biasanya terjadi perlahan-lahan dalam jangka waktu yang lama sehingga kurangnya kesadaaran terhadap dampak dari penurunan tanah yang dapat menggangu kesejahteraan penduduk. Studi ini dilakukan untuk mengetahui karakteristik penduduk, keterkaitan antara penurunan tanah dengan kondisi eksisting, rencana pemerintah dalam Rencana Detail Tata Ruang (RDTR), dan perbandingan kondisi dan penaganan pemerintah pada wilayah penurunan tanah dengan menggunakan metode analisisi deskriptif, komparatif, overlay, dan kuesioner. Untuk mencapai tujuan tersebut dilakukan analisis kependudukan, analisis penurunan tanah terhadap kondisi eksiting, analisis rencana detail tata ruang, dan analisis best practices. Dengan ini maka dapat dihasilkan saran adaptasi pada wilayah rawan penurunan tanah bagi penduduk, pengembang, dan pemerintahan agar dapat ikut berperan dalam menghambat laju penurunan tanah. Studi ini menghasilkan kesimpulan dan saran adaptasi penurunan tanah yang dilakukan oleh penduduk, pemerintahan, dan pengembang.
\end{abstract}

Kata kunci: Adaptasi; Kecamatan Cengkareng; Penurunan Tanah

\begin{abstract}
Land subsidence is one of the natural phenomena that occurs in the city of Jakarta, one of which is in Cengkareng District. Land subsidence is caused by several factors such as natural factors, groundwater extraction factors, and building mass factors. This land subsidence usually occurs slowly over a long period of time so that there is a lack of awareness of the impact of land subsidence that can interfere with the welfare of the population. This study was conducted to determine the characteristics of the population, the relationship between land subsidence and existing conditions, the government's plan in the Detailed Spatial Planning (RDTR), and a comparison of the conditions and government management in land subsidence areas using descriptive, comparative, overlay, and questionnaire analysis methods. To achieve these objectives, population analysis, land subsidence analysis on the existing condition, analysis of detailed spatial plans, and analysis of best practices are carried out. With this it can be produced adaptation suggestions in areas prone to land subsidence for residents, developers, and the government so that they can play a role in inhibiting the rate of land subsidence. This study produces conclusions and suggestions for adaptation to land subsidence carried out by residents, government, and developers.
\end{abstract}

Keywords: Adaptation; Cengkareng District; Landsubsidence 


\section{PENDAHULUAN}

\section{Latar Belakang}

Kota Jakarta merupakan Ibukota negara Indonesia yang memiliki peran penting sebagai pusat kegiatan, pusat pemerintahan, bisnis, budaya dan merupakan daerah otonom. Seiring perkembangan Kota Jakarta yang semakin meningkat dengan adanya pembangunan gedung- gedung bertingkat, sarana, prasarana, dan aksesibilitas yang berkembang untuk melayani kebutuhan masyarakat. Perkembangan yang terjadi diikuti dengan berbagai karakteristik permasalahan perkotaan seperti salah satunya yang sedang dialami Kota Jakarta yaitu penurunan tanah. Penurunan tanah dapat disebabkan oleh beberapa faktor seperti, faktor alami, faktor pengambilan air tanah, dan faktor massa bangunan. Adapun dampak dari penurunan tanah seperti, menyebabkan banjir rob, terdapat genangan air hujan, rusaknya infrastruktur, inturusi air laut, dan kualitas hidup menurun. Penurunan tanah terdalam pada Kota Jakarta salah satunya terdapat di Kecamatan Cengkareng.

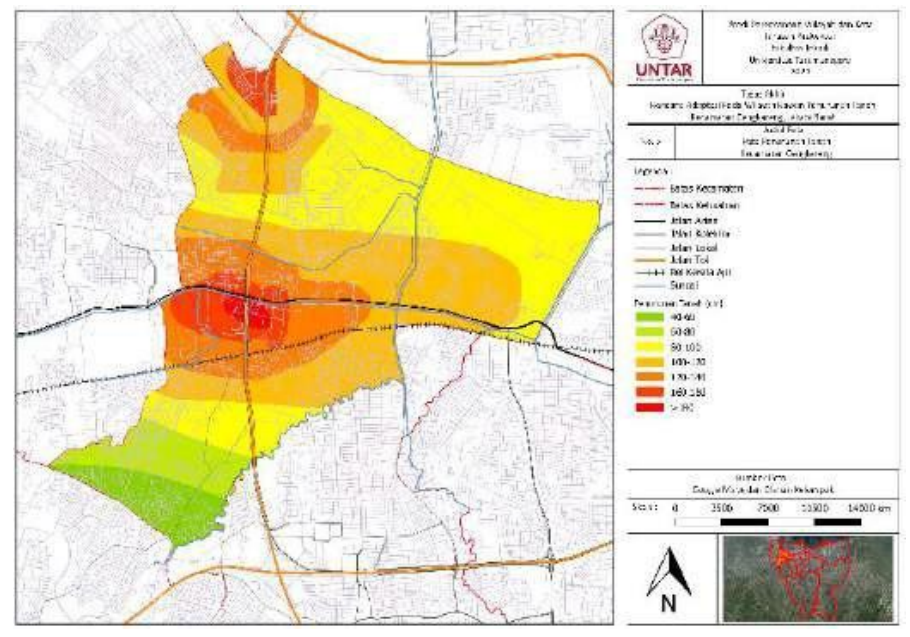

Gambar 1. Penurunan Tanah Kecamatan Cengkareng Sumber: Pemerintahan Provinsi DKI Jakarta

Dalam menangani penurunan tanah dibutuhkan peran penduduk, pengembang, dan pemerintah dalam menghambat laju penurunan tanah yang telah terjadi dengan melakukan tindakan penyesuaian diri atau adaptasi terhadap penurunan tanah. Peran penduduk dan pengembang dibutuhkan dalam melakukan adaptasi dikarenakan dampak dari penurunan tanah dirasakan langsung oleh penduduk dan pengembang. Serta, peran pemerintah dalam menangi penurunan tanah dilakukan melalui program-program yang telah dibuat untuk menangani penurunan tanah serta rencana tata ruang berupa Rencana Detail Tata Ruang yang merupakan rencana yang akan dilakukan di masa mendatang. Dengan ini maka dibutuhkannya adaptasi yang sesuai untuk mengani peurunan tanah di Kecamatan Cengkareng.

\section{Rumusan Permasalahan}

Terjadinya penurunan tanah pada Kecamatan Cengkareng yang dapat berdampak terhadap kondisi infrastruktur, bangunan, ekonomi, lingkungan, dan sosial dengan adanya fenomena tersebut maka diperlukan adaptasi penduduk, pengembang, dan pemerintah dalam menangani penurunan tanah di Kecamatan Cengkareng.

\section{Tujuan}

Studi ini dilakukan untuk mengetahui karakteristik penduduk, keterkaitan antara penurunan tanah dengan kondisi eksisting, rencana pemerintah dalam Rencana Detail Tata Ruang (RDTR), perbandingan kondisi dan penaganan pemerintah pada wilayah penurunan tanah, serta memberi saran mengenai rencana adaptasi yang sesuai pada wilayah penurunan tanah pada Kecamatan Cengkareng bagi penduduk, pengembang, dan pemerintah. 


\section{KAJIAN LITERATUR}

\section{Penurunan Tanah}

Penurunan tanah atau Land Subsidence merupakan suatu proses gerakan penurunan tanah yang didasarkan atas suatu datum tertentu (kerangka referensi geodesi) dimana terdapat berbagai macam variabel penyebabnya (Marfai, 2006). Penurunan tanah berlangsung dalam waktu yang singkat dan persebaran penurunan muka tanah tidak terjadi di setiap lokasi (Ahzab dkk, 2016). Menurut ilmuwan Whittaker dan Reddish, 1998 terdapat tiga penyebab penurunan tanah yaitu, faktor alami, faktor pengambilan air tanah, dan faktor massa bangunan. Menurut Abidin et al., 2015 dalam Kajian Mengenai Resiko dan Dampak Penurunan Tanah di Jakarta digambarkan sebagai berikut.

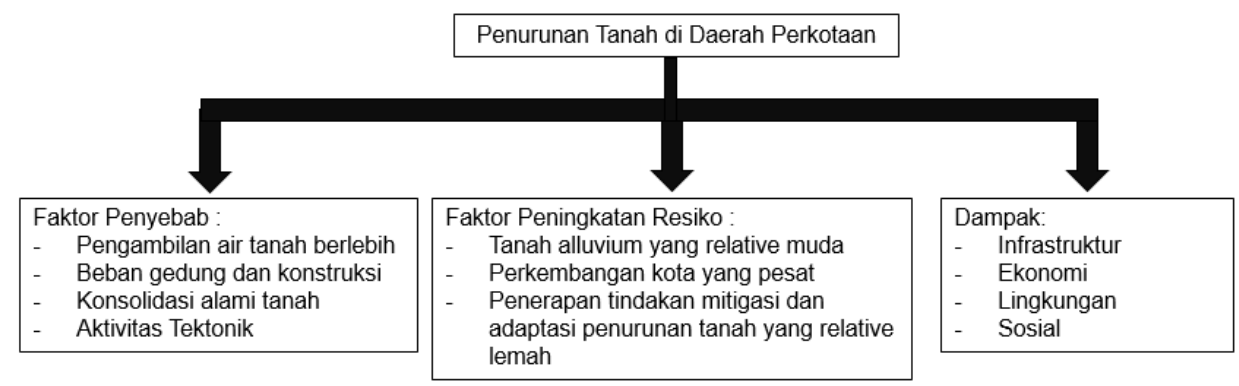

Gambar 2. Faktor Penyebab, Faktor Peningkatan Risiko Dan Dampak Penurunan Muka Tanah Di Wilayah Perkotaan Di Indonesia

Sumber: Kajian Mengenai Resiko dan Dampak Penurunan Tanah di Jakarta (Abidin et al., 2015)

Berdasarkan dari grafik diatas penurunan tanah yang terjadi di daerah perkotaan seperti Jakarta dapat disebabkan oleh empat faktor yaitu, pengambilan air tanah yang berlebih, beban gedung dan konstruksi, konsodalitasi alami tanah dan aktvitas tektonik. Terdapat juga faktor yang dapat meningkatkan resiko penurunan tanah seperti, tanah alluvium yang realtif muda, perkembangan kota yang pesat, serta penerapan tindakan mitigasi dan adaptasi yang realtif lemah.

\section{Adaptasi}

Adaptasi merupakan suatu strategi untuk penyesuaian diri yang digunakan manusia selama hidupnya untuk merespon terhadap perubahan-perubahan lingkungan dan sosial (Alland, dkk, dalam Gunawan B,2008). Menurut Rambo (1984) adaptasi dilakukan manusia terhadap lingkungan menunjukan adanya interelasi antara manusia dan lingkungan. Moran (1982) mengatakan bahwa ketika suatu populasi masyarakat mulai menyesuaikan diri terhadap suatu lingkungan yang baru, suatu proses perubahan akan dimulai dan mungkin membutuhkan waktu yang lama untuk dapat menyesuaikan diri.

\section{Best Practice}

Best practice merupakan ide atau gagasan mengenai suatu teknik, metode, proses, aktivitas, dan penghargaan yang efektif dalam mencapai keberhasilan yang luar biasa dibandingkan dengan teknik, metode, proses yang lain (Sutikno, 2010). Best practice adalah cara yang memiliki efisiensi dan efektivitas yang tinggi untuk menyelesaikan suatu masalah. Menurut penilaian UN Habitat mengenai best practice (Prasojo et al, 2007: 6) mendefinisikan best practice dalam konteks lingkungan perkotaan sebagai inisiatif yang telah menghasilkan kontribusi yang terlihat dalam meningkatkan kualitas kehidupan baik di perkotaan maupun masyarakat.

\section{Rencana Detail Tata Ruang}

Rencana Detail Tata Ruang (RDTR) merupakan produk penataan ruang dalam skala terkecil pada kabupaten atau kota, penjabaran dari Rencana Tata Ruang Wilayah (RTRW) Kabupaten yang ditetapkan sebagai perencanaan lingkup kabupaten atau kota secara nasional pada tahun 2002. 
Menurut PERMEN Agraria dan Tata Ruang No. 16 Tahun 2018, tentang pedoman penyusunan RDTR dan peraturan zonasi kabupaten/kota RDTR merupakan rencana terpernci tentang tata ruang wilayah kabupaten/kota yang dilengkapi dengan peraturan zonasi kabupaten/kota yang dijadikan sebagai acuan bagi Pemerintah Daerah Kabupaten/Kota dalam menyusun keterangan rencana kabupaten/kota sesuai dengan ketentuan peraturan perundang-undangan.

\section{METODE}

Studi ini dilakukan di Kecamatan Cengkareng menggunakan mendekatan kualitatif dengan metode penggumpulan data sekunder dan primer, dengan melakukan survey lapangan, wawancara, dokumentasi, kuesioner, dan studi litelatur. Dalam melakukan studi ini dibutuhkan data mengenai data demografi Kecamatan Cengkareng, data kondisi eksiting yang berisi data laju penurunan tanah, penggunaan lahan eksisting, ketinggian bangunan eksting, penggunaan air eksisting, topografi, dan lokasi banjir, lalu data Rencana Detail Tata Ruang tahun 2030, dan data pembanding berupa data program pemerintah dalam menangani penurunan tanah pada Kecamatan Cengkareng dan Kecamatan Penjaringan.

Berdasarkan dari data yang didapatkan dilakukan analisis berupa analisis kependudukan, analisis penurunan tanah terhadap kondisi eksisting, analisis rencana tata ruang, dan analisis best practice. Analisis dilakukan menggunakan metode deskriptif, komperatif, overlay, dan kuesioner. Analisisanalisis tersebut dilakukan untuk mengetahui karakteristik penduduk dan penilaian kognitif terhadap lingkungan penduduk, keterkaitan antara kondisi eksisting dengan laju penurunan tanah, rencana pemerintah pada wilayah penurunan tanah berdasarkan Rencana Detail Tata Ruang (RDTR), dan perbandingan kondisi dan penangan pemerintah pada Kecamatan Cengkareng dan Kecamatan Penajringan. Dengan ini maka dapat menghasilkan kesimpulan mengenai rencana adaptasi yang sesuai pada wilayah rawan penurunan tanah, Kecamatan Cengkareng, Jakarta Barat.

\section{DISKUSI DAN HASIL}

\section{Kependudukan}

Kecamatan Cengkareng merupakan kecamatan dengan kepadatan penduduk sedang hingga tinggi dan proyeksi penduduk tahun 2029 dan 2039 diprediksikan dengan kepadatan penduduk yang tinggi. Berdasarkan hasil kuesioner yang telah disebarkan dapat diketahui bahwa penduduk merasakan adanya sumber atau stimulus yang dapat mengganggu kesejahteraan seperti banjir, kerusakan infrastruktur, kondisi drainase yang tidak memadai, dan keretakan pada bangunan yang merupakan reaksi tanda bahaya dikarenakan kondisi lingkungan tempat tinggal yang disebabkan oleh penurunan tanah. Namun, masih kurangnya pengetahuan masyarakat mengenai dampak dari penurunan tanah dengan ini maka dibutuhkannya adaptasi penduduk terhadap penurunan tanah.

\section{Penurunan Tanah Terhadap Kondisi Eksisting}

Penurunan tanah terhadap kondisi eksisting dilakukan untuk mengetahui keterkaitan antara penurunan tanah terhap kondisi esksitng yang terbagi atas beberapa kondisi eksisting yaitu, penggunaan lahan eksisting, ketinggian bangunan eksisting, penggunaan air bersih, topografi, dan banjir. 

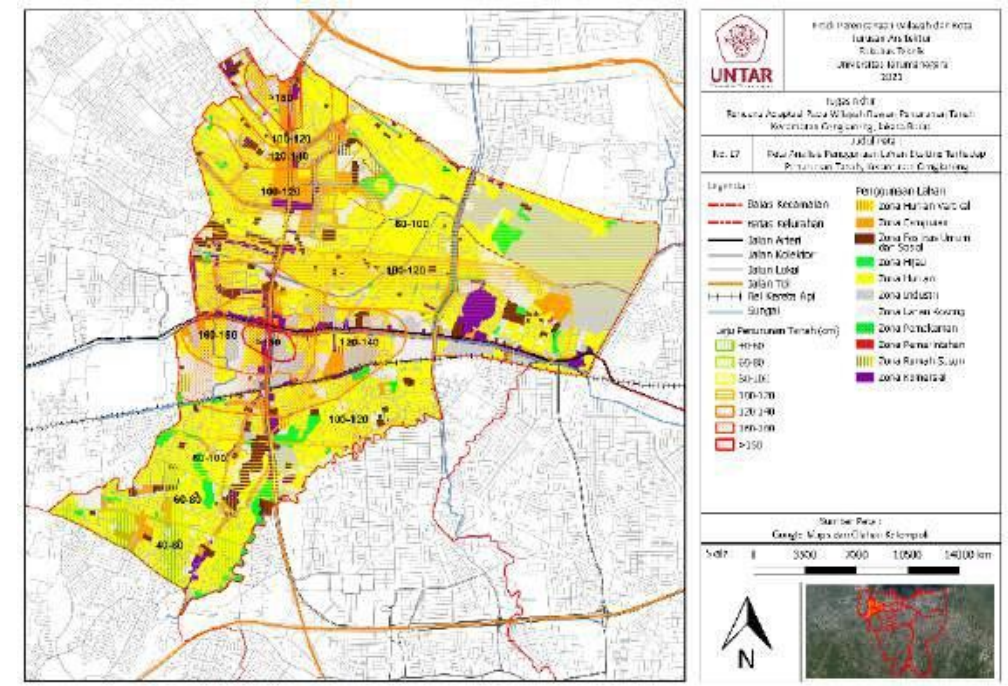

Gambar 3. Analisis Penurunan Tanah Terhadap Penggunaan Lahan Eksiting Sumber: Olahan Penulis

Pada wilayah penurunan tanah tidak terdapat perbedaan penggunaan lahan di setiap laju penurunan tanahnya. Penggunaan lahann eksisting yang dominan pada seluruh laju penurunan tanah adalah zona hunian yang dimana zona hunian merupakan area terbangun yang berpotensi meningkatkan laju terjadinya penurunan tanah dibandingkan dengan area tidak terbangun / open space. Selain itu ketinggian bangunan juga memiliki potensi untuk meningkatkan laju penurunan tanah ketinggian bangunan yang berbeda-beda menimbulkan beban atas bangunan yang berbeda-beda, semakin tinggi suatu bangunan maka beban atas bangunan pun semakin tinggi dan sebaliknya yang dapat mendukung penurunan tanah.
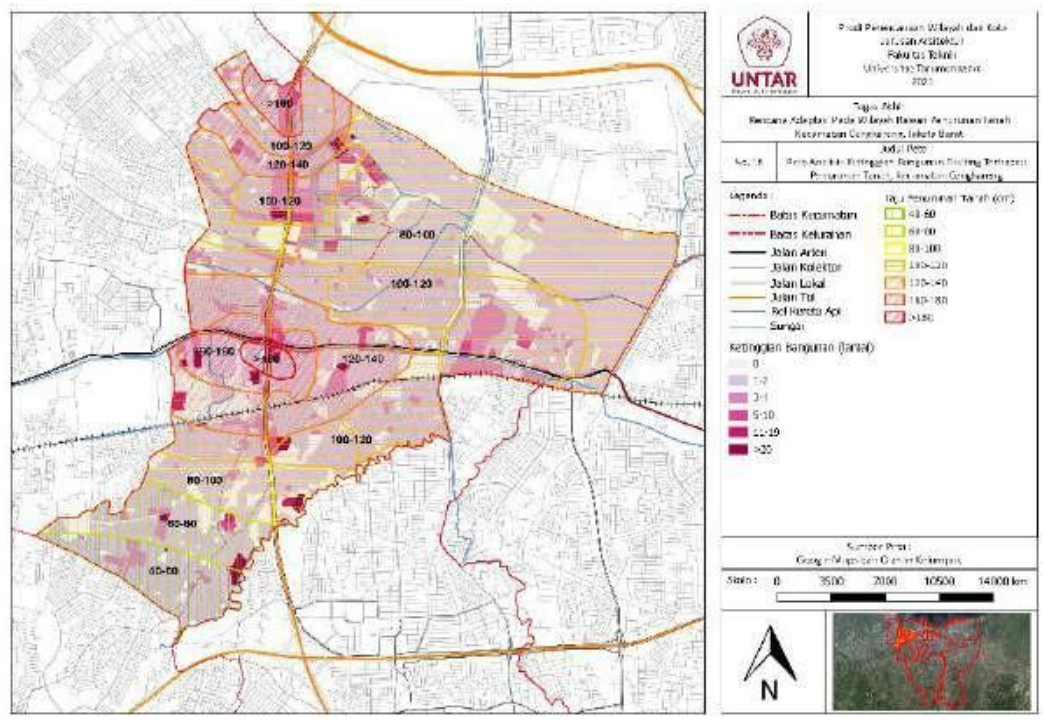

Gambar 4. Analisis Penurunan Tanah Terhadap Ketinggian Bangunan Eksiting Sumber: Olahan Penulis

Berdasarkan pada peta diatas dapat diketahui bahwa ketinggian bangunan pada wilayah penurunan tanah di dominasi oleh ketinggian bangunan 1-2 lantai yang merupakan bangunan rendah. Pada laju penurunan tanah $>120 \mathrm{~cm}$ terdapat bangunan lebih dari 5 lantai. Maka dari ini dapat dikatakan bahwa, ketinggian bangunan eksisting Kecamatan Cengkareng belum mempertimbangkan adanya penurunan tanah pada wilayah tersebut dan dapat mendukung laju penurunan tanah semakin 
dalam. Selanjutnya terdapat pembahasan mengenai penurunan tanah terhadap kondisi eksisting pengambilan air bersih.
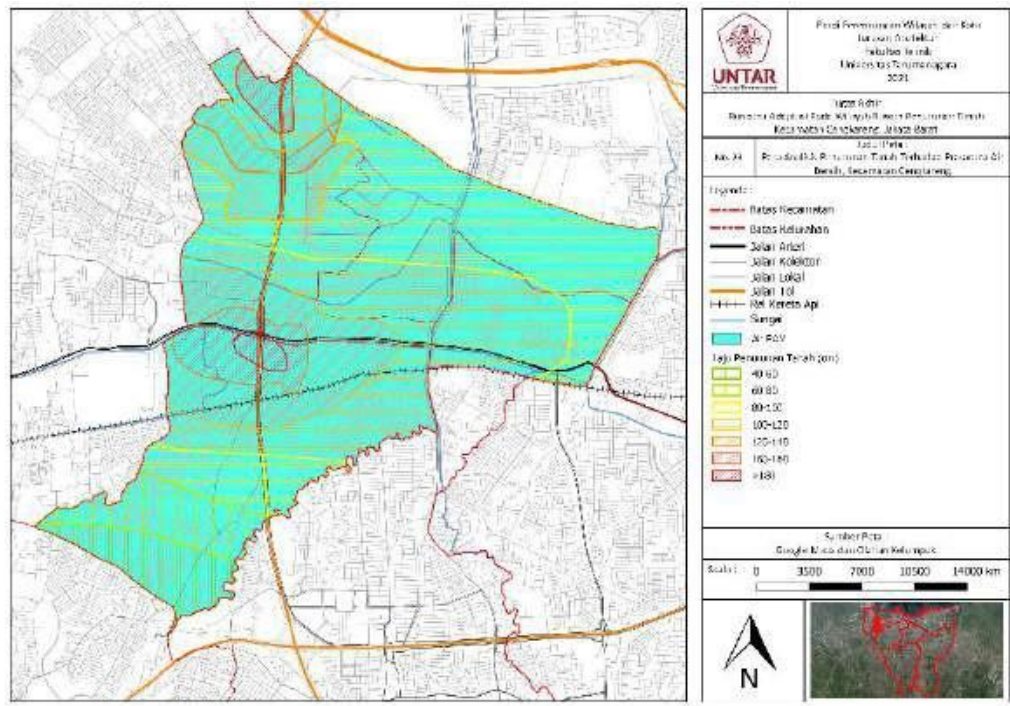

Gambar 5.Analisis Penurunan Tanah Terhadap Sumber Air Sumber: Olahan Penulis

Pada seluruh wilayah penurunan tanah dengan laju yang berbeda-beda telah menggunakan air PAM sebagai sumber air bersih untuk kegiatan sehari-hari. PT. PALYJA merupakan operator penyediaan air PAM di Kecamatan Cengkareng mendapatkan air dari Instalasi Pengolahan Air (IPA) Cisadan, Instalasi Pengolahan Air 2 (IPA 2) Pejompongan, dan Instalasi Pengolahan Air (IPA) Kelapa Dua. Penggunaan air PAM pada wilayah penurunan tanah merupakan salah cara untuk menguranggi laju penuruna tanah maka dari itu, tidak adaanya keterkaitan antara penggunaan air bersih eksisting dengan penurunan tanah. Selanjutnya berikut merupakan pembahasan mengenai penurunan tanah terhadap topografi.

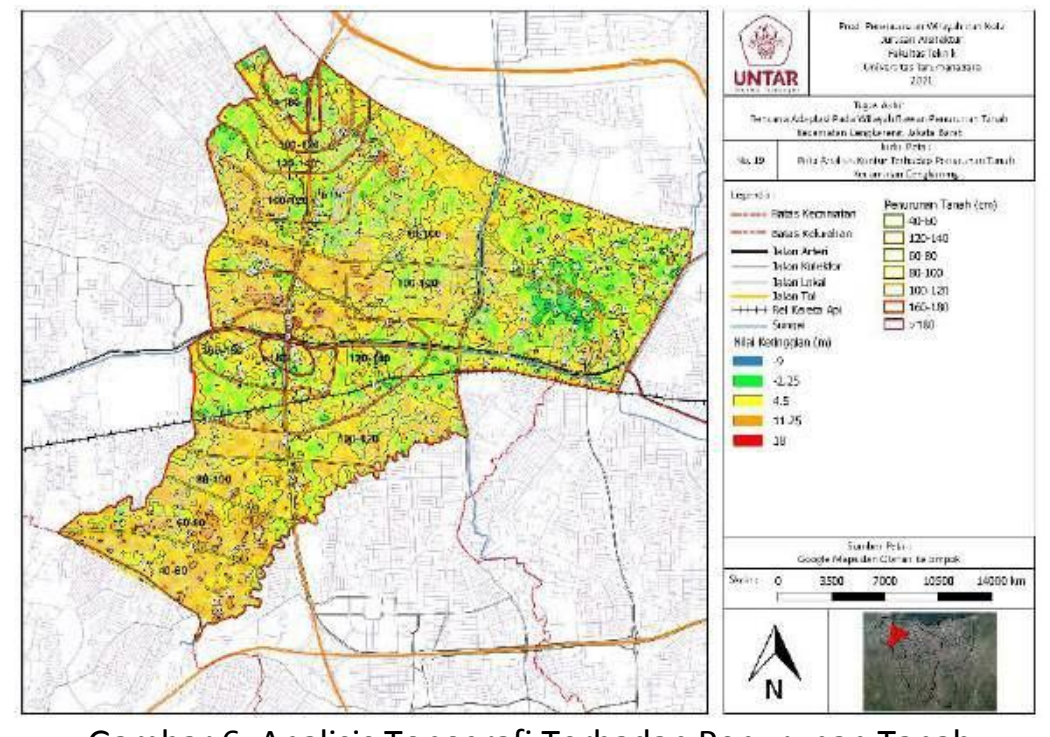

Gambar 6. Analisis Topografi Terhadap Penurunan Tanah Sumber: Olahan Penulis

Topografi Kecamatan Cengkareng relative datar dengan nilai ketinggian yang rendah dari $-2.25-4.5$ m berdasarkan referensi tinggi EGM96 (The Earth Gravityational Models). Berdasarkan pada peta 
diatas dapat ketahui bahwa pada wilayah laju penurunan tanah $40-80 \mathrm{~cm}$ berada pada dataran yang lebih tinggi dibangingkan wilayah dengan laju penurunan tanah lainnya namun, pada wilayah dengan laju penurunan tanah $>80 \mathrm{~cm}$ berada pada dataran yang bervariasi mulai dari $-2.25-4.5 \mathrm{~m}$. Dengan ini maka, adanya keterkaitan antara laju penurunan tanah dengan topografi, semakin dalam laju penurunan tanah maka memungkinkan dataran menjadi lebih rendah dinbandingkan wilayah laju penurunan lainnya. Setelah itu terdapat pembahasan menegani penurunan tanah terhadap banjir.

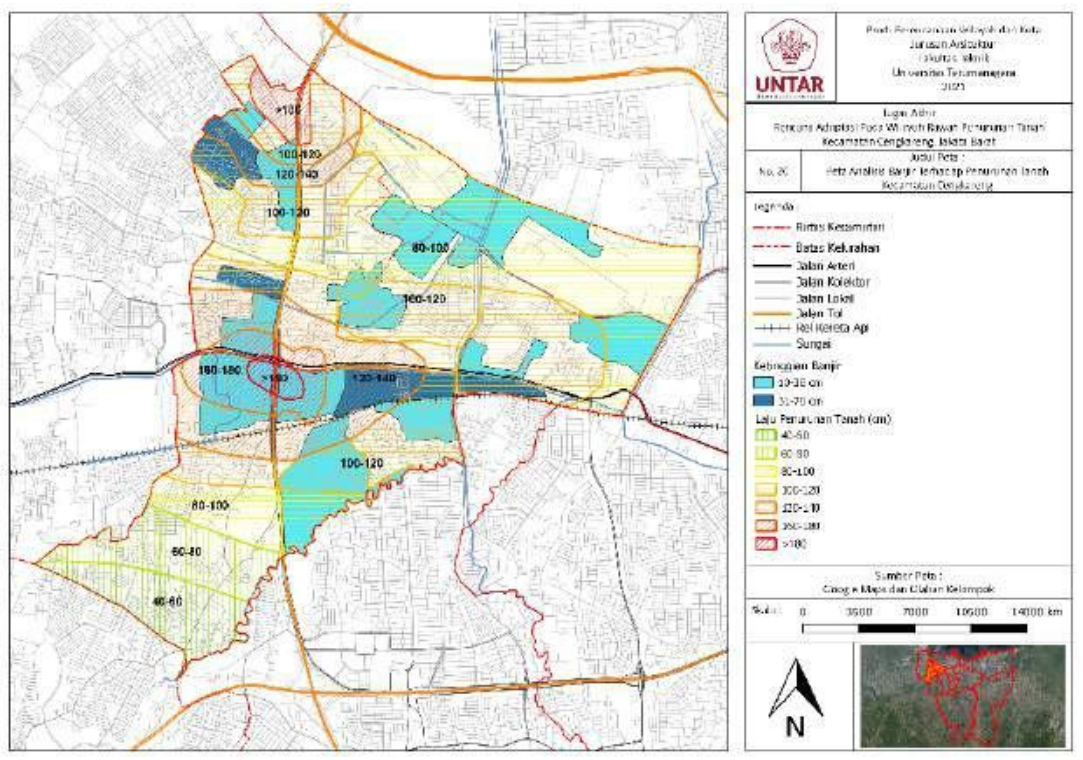

Gambar 7. Analisis Penurunan Tanah Terhadap Banjir

Sumber: Olahan Penulis

Berdasarkan peta diatas banjir terjadi pada mulai dari penurunan tanah $80 \mathrm{~cm}$ hingga $>180 \mathrm{~cm}$ dengan ketinggian banjir 10-30 dan 31-70 cm. Banjir dengan ketinggian 31-70 $\mathrm{cm}$ terdapat pada laju penurunan 100-120 dengan luas $0,58 \mathrm{~km}^{2}$ dan $120-140 \mathrm{~cm}$ dengan luas $0,66 \mathrm{~km}^{2}$ lain halnya pada laju $>180 \mathrm{~cm}$ hanya terdapat banjir dengan ketinggian $10-30 \mathrm{~cm}$. Penurunan tanah bukan satu-satunya faktor terjadinya banjir pada Kecamatan Cengkareng. Berdasrkan peta analisis penurunan tanah terhadap banjir, beberapa lokasi banjir yang terjadi berada sepanjang Kali Mookervart yang dapat dikarenakan meluapnya air Kali Mookervart. Dengan ini maka tidak adanya keterkaitan antara banjir dengan penurunan tanah, karena penurunan tanah bukan satu-satunya penyebab terjadinya banjir di Kecamatan Cengkareng, lokasi banjir yang berdekatan dengan Kali Mookervart juga dapat merupakan faktor pendukung terjadinya banjir, dikarenakan adanya luapan air dari Kali Mookervart.

\section{Rencana Detail Tata Ruang (RDTR)}

Dalam Rencana Detail Tata Ruang (RDTR) terdapat rencana penggunaan lahan dan batas ketinggian bangunan yang telah di tetapkan dalam RDTR pada wilayah yang mengalami penurunan tanah. Pembahasan kali ini dilakukan untuk mengetahui apakah RDTR telah mempertimbangkan penurunan tanah sebagai salah satu aspek dalam membuat rencana tata ruang. Berikut merupakan pembahasan mengenai laju penurunan tanah terhadap penggunaan lahan RDTR 2030. 


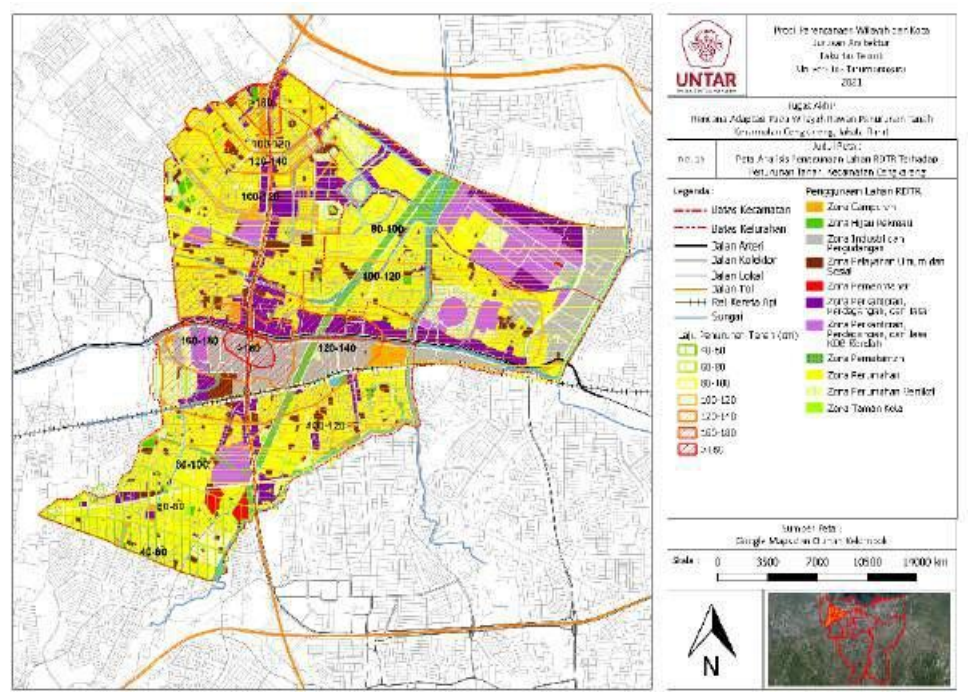

Gambar 8. Analisis Penggunaan Lahan RDTR 2030 pada Wilayah Penurunan Tanah Sumber: Olahan Penulis

Berdasarkan penggunaan lahan RDTR pada wilayah penurunan tanah dengan laju $>180$ terdapat zona industri, dan zona campuran, sedangkan pada laju 160-180 cm terdapat zona hunian, campuran, pelayanan umum dan sosil, perkontoran, perdangangan dan jasa, industry, dan zona hijau. Pada seluruh wilayah penurunan tanah tidak terdapat perbedaan yang signifikan pada penggunaan lahannya dengan KDB area terbangun 40-60 dan 0 pada area tidak terbangun. Lalu berikut merupakan pembahasan mengenai laju penurunan tanah teradap ketinggian bangunan RDTR 2030.

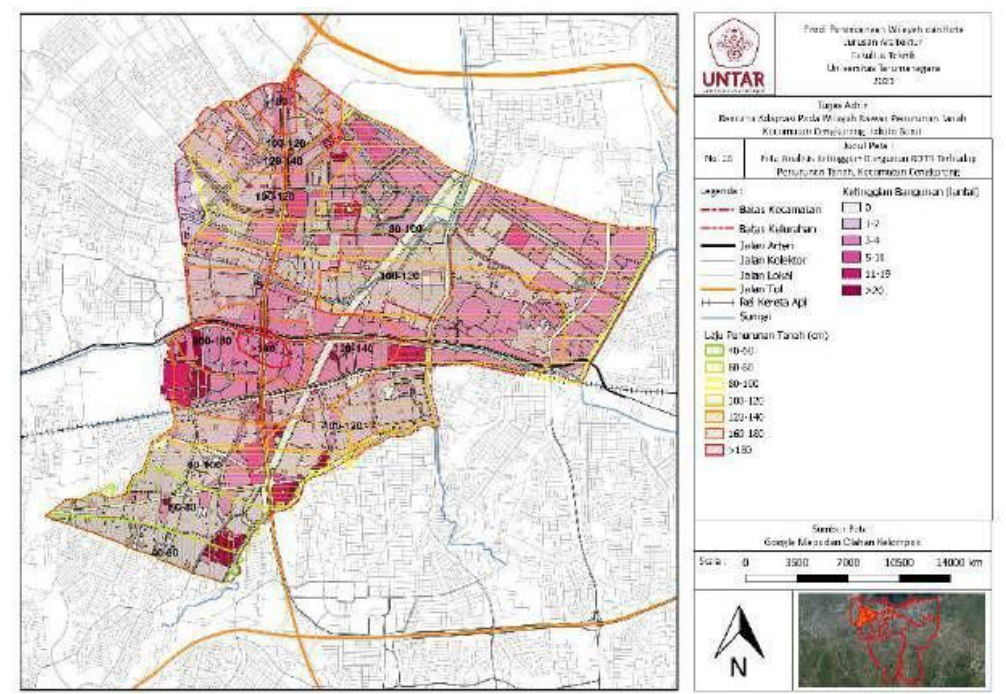

Gambar 9. Analisis Ketinggian Bangunan RDTR 2030 pada Laju Penurunan Tanah Sumber: Olahan Penulis

Dalam RDTR tahun 2030 pada wilayah rawan penurunan tanah di Kecamatan Cengkareng pada laju penurunan 120-140 cm masih diperbolehkan bangunan dengan ketinggian lebih dari 10 lantai bahkan hingga lebih dari 20 lantai begitu pula pada wilayah dengan laju penurunan 160- $180 \mathrm{~cm}$. Pada laju penurunan $>180 \mathrm{~cm}$ terdapat lokasi yang masih diperbolehkan dengan ketinggian 11-19 lantai. Maka, dapat dikatakan RDTR yang ada belum mempertimbangkan penurunan tanah sebagai salah satu faktor dalam merancana RDTR. 


\section{Best Practices}

Best Practices dilakukan untuk membandingkan kondisi wilayah dan adaptasi yang dilakukan pemerintah pada objek studi dengan objek serupa yang mengalami penurunan tanah yaitu Kecamatan Penjaringan, Jakarta Utara untuk mengetahui adaptasi yang sesuai bagi Kecamatan Cengkareng. Kecamatan Penjaringan merupakan daerah yang mengalami penurunan tanah dalam di Jakarta. Berikut merupakan perbandingan berdasarkan kondisi pada aspek-aspek terjadinya pendukung penurunan tanah pada objek studi dan juga objek pembanding.

Tabel 1. Objek Pembanding Kondisi Terjadinya Penurunan Tanah

\begin{tabular}{ccc}
\hline Kecamatan & Aspek & Kondisi \\
\hline Cengkareng & Sejarah & Wilayah rawa dan persawahan \\
\cline { 2 - 3 } & Bangunan & Terdapat bangunan tinggi \\
\cline { 2 - 3 } & Ruang Terbuka Hijau & Kurang dari 5\% \\
\cline { 2 - 3 } & Penggunaan Air & Air PAM \\
\hline Penjaringan & Sejarah & Wilayah rawa dan pelabuhan \\
\cline { 2 - 3 } & Buangunan & Terdapat bangunan tinggi \\
\cline { 2 - 3 } & Penggunaan Air & Kurang dari 5\% \\
\cline { 2 - 3 } & & Air PAM \\
\end{tabular}

Sumber: Olahan Penulis

Kondisi pada wilayah terjadinya penurunan tanah dilihat berdasarkan kondisi sejarah, bangunan, kawasan, sumber air, dan ruang terbuka hijau. Berdasarkan pada tabel diatas dapat diketahui Kecamatan Cengkareng dan Kecamatan Penjaringan yang merupakan objek pembanding memiliki kondisi pendukung terjadinya penurunan tanah. Pada kondisi dengan aspek sejarah, bangunan, dan ruang terbuka hijau Kecamatan Cengkareng dan Kecamatan Penjaringan memiliki kondisi yang mendukung untuk terjadinya penurunan tanah, hanya pada aspek sumber air yang memiliki kondisi kurang mendukung dikarenakan pada kedua wilayah tersebut telah menggunakan air PAM sebagai sumber air. Dalam melakukan Best Practices juga terdapat perbandingan terhadap penanganan pemerintah pada wilayah rawan terjadinya penurunan tanah. Berikut merupakan perbandingan penanganan pada wilayah rawan terjadinya penurunan tanah oleh pemerintah.

Tabel 2. Perbandingan Penanganan Pada Wilayah Rawan Terjadinya Penurunan Tanah Oleh

Pemerintah

\begin{tabular}{ll}
\hline \multicolumn{1}{c}{ Kecamatan Cengkareng } & \multicolumn{1}{c}{ Kecamatan Penjaringan } \\
\hline $\begin{array}{l}\text { Menyediakan air bersih melalui jaringan Sistem } \\
\text { Penyediaan Air Minum (SPAM) }\end{array}$ & $\begin{array}{l}\text { Menyediakan air bersih melalui jaringan Sistem } \\
\text { Penyediaan Air Minum (SPAM) }\end{array}$ \\
\hline $\begin{array}{l}\text { Membangun pengolahan air limbah (program } \\
\text { Sistem Pengelolaan Air Limbah Terpadu atau } \\
\text { Jakarta Sewerage System (JSS)) }\end{array}$ & $\begin{array}{l}\text { Membangun pengolahan air limbah (program Sistem } \\
\text { Pengelolaan Air Limbah Terpadu atau Jakarta Sewerage } \\
\text { System (JSS)) }\end{array}$ \\
\hline Pengelolaan drainase (program Sanimas) & Pengelolaan drainase ( program Sanimas) \\
\hline & $\begin{array}{l}\text { Membangun tanggul laut raksasa (program Quick Win } \\
\text { Pembangunan Terpadu Pesisir Ibukota Negara (PTPIN) }\end{array}$ \\
atau National Capital Integrated Coastal Development \\
(NCICD))
\end{tabular}

Sumber: pu.go.id dan Olahan Penulis

Kecamatan Cengkareng merupakan wilayah terjadinya penurunan tanah di tengah kota dan Kecamatan Penjaringan merupakan wilayah terjadinya penurunan tanah yang berada dekat dengan 
laut. Kondisi geografis yang berbeda antara kedua kecamatan tersebut membuat pemerintah melakukan penanganan yang berbeda. Pada Kecamatan Cengkareng dilakukan penanganan dalam penggunaan air dan pengelolaan air limbah serta drainase, sedangkan dikarenakan Kecamatan Penjaringan berdekatan dengan laut maka terdapat beberapa penanganan yang dilakukan pemerintah untuk mengurangi dampak dari penurunan tanah dengan pembangunan tanggul laut dan peninggian tanggul pada pesisir pantai di Kecamatan Penajaringan.

\section{KESIMPULAN DAN SARAN}

\section{Kesimpulan}

Penurunan tanah merupakan salah satu fenomena alam yang terjadi di berbagai wilayah salah satunya yaitu Kecamatan Cengkareng. Pada Kecamatan Cengkareng terjadi laju penurunan tanah sebesar 40 hingga lebih dari $180 \mathrm{~cm}$. Penurunan tanah yang terjadi berkaitan pada kondisi lingkungan maupun penduduk yang tinggal pada wilayah penurunan tanah. Penduduk Kecamatan Cengkareng termasuk pada kepadatan penduduk sedang hingga tinggi dan berdasarkan hasil pesebaran kuesioner penduduk merasakan adanya sumber atau stimulus yang dapat mengganggu kesejahteraan dari dampak terjadinya penurunan tanah. Stimulus tersebut merupakan reaksi tanda bahaya terhadap dampak penurunan tanah dengan ini maka dibutuhkannya adaptasi terhadap penurunan tanah untuk penduduk, pengembang, serta pemerintah.

Penurunan tanah juga saling mempengaruhi satu sama lain dengan kondisi eksiting seperi penggunaan lahan, ketinggian bangunan, sumber air bersih, topografi, dan banjir. Pada Kecamatan Cengkareng kondisi eksisiting penggunaan lahan dan ketinggian bangunan memiliki keterkaitan dengan penurunan tanah dan berpotensi meningkatkan resiko terjadinya penurunan tanah serta terdapat kerterkaitan pada kondisi topografi, semakin dalam laju penurunan tanah maka memungkinkan dataran menjadi lebih rendah di bandingkan wilayah laju penurunan lainnya. Namun, penurunan tanah pada Kecamatan Cengkareng tidak berkaitan dengan kondisi banjir di wilayah tersebut dan kondisi sumber air bersih sudah menggunakan air PAM sebagai salah satu cara untuk mengurangi penurunan tanah.

Dalam menangani penurunan tanah pemerintah melakukan penanganan melalui berbagai program serta dalam Rencana Detail Tata Ruang (RDTR). Dalam RDTR masih diperbolehkan bangunan tinggi dengan ini maka dapat dikatakan RDTR yang ada belum mempertimbangkan penurunan tanah sebagai salah satu faktor dalam merancana RDTR. Selain untuk mengetahui adaptasi yang sesuai bagi Kecamatan Cengkareng penulis membandingkan kondisi wilayah dan adaptasi yang dilakukan dari pemerintah pada objek studi dengan objek serupa yang mengalami penurunan tanah yaitu Kecamatan Penjaringan, Jakarta Utara. Kecamatan Penjaringan merupakan daerah yang mengalami penurunan tanah dalam di Jakarta. Kecamatan Cengkareng dan Kecamatan Penjaringan memiliki kesamaan pada kondisi pendukung terjadinya penurunan tanah. Adaptasi pemerintah melakukan penanganan pada kedua wilayah tersebut namun penangan yang dilakukan berbeda dikarenakan kondisi geografi yang mempengaruhi dampak penurunan tanah pada kedua wilayah tersebut.

\section{Saran}

Terdapat beberapa saran adaptasi pada wilayah rawan penurunan yang dapat dilakukan oleh penduduk, pengembang, dan pemerintah. Saran adaptasi untuk penduduk yaitu dengan, menaikan ketinggian dasar bangunan, menggunakan air PAM sebagai sumber air, dan melakukan pemeliharaan lingkungan secara berkala seperti pembersihan drainase dan merawat bangunan. Untuk pemerintah dapat melakukan adaptasi dengan melakukan pemantauan terhadap penurunan tanah, memberikan informasi dan penyuluhan secara berkala mengenai kondisi penurunan tanah kepada penduduk untuk meningkatkan kesadaran terhadap penurunan tanah, menambah ruang terbuka hijau, memperketat peraturan mengenai pengambilan air tanah, memasukan penurunan tanah sebagai salah satu aspek dalam membuat RDTR, melakukan pembatasan serta pemantauan 
ketinggian bangunan tinggi pada wilayah dengan penurunan tanah. Untuk pengembang dengan melakukan adaptasi yaitu, mematuhi peraturan pemerintah mengenai pembatasan ketinggian bangunan, tidak membuang limbah langsung ke drainase, merawat bangunan secara berkala agar tidak mudah retak.

\section{REFERENSI}

Abidin, H.Z., Andreas, H., Gumilar, I., dan Brinkman, J.J. (2015). Study on The Risk and Impacts of Land Subsidence in Jakarta.

Abidin, Hasanuddin Z., et al (2011). Land Subsudence of Jakarta (Indonesia) and Its Relation with Urban Development.

Abidin, H.Z., Andreas, I., Wibowo, I.R.R. (2015). On Correlation between Urban Development, Land Subsidence and Flooading Phenomena in Jakarta.

Helmi, Avin Fadilla. (1999). Beberapa Teori Psikologi Lingkungan. Buletin Psikologi. Tahun VII No. 2 Desember 1999.

ilmugeografi. (diakses 01.10.20/13.00). Fenomena Alam Penurunan Muka Tanah. (https://ilmugeografi.com/fenomena-alam/penurunan-muka-tanah)

Biro Komunikasi Publik. (diakses 28.06.21/13.50). 2017. Atasi Laju Penurunan Permukaan Tanah DKI Jakarta, Kementrian PUPR Siapkan Langkah Quick Wiins. (https://pu.go.id/berita/atasi-laju- penurunan-permukaan-tanah-dki-jakartakementerian-pupr-siapkan-langkah-quick-wins)

Pramono, FX. Richard. (diakses 05.05.2021/14.21). 2016. Journal: Tanah Ambles Ibu Kota. (https://www.liputan6.com/news/read/2469641/journal-tanah-ambles-ibukota\#) 
